\title{
O Fazer Psicológico na Ditadura Civil Militar
}

\author{
Ana Maria Batista Correia \\ Universidade Federal do Piauí, PI, Brasil.
}

\author{
Carla Náyad Castelo Branco Dantas \\ Universidade Paulista, SP, Brasil.
}

\begin{abstract}
Resumo: O presente artigo apresenta discussão sobre o fazer $p$ si na época da ditadura civil militar, objetivando responder ao seguinte questionamento: a Psicologia brasileira esteve a serviço da ditadura civil militar ou da sociedade?. Considerando que a regulamentação da profissão de psicólogo em 1962 coincidiu com o período ditatorial vivenciado no Brasil entre os anos de 1964 a 1985, objetivamos discutir sobre o desenvolvimento da Psicologia como ciência e profissão neste contexto turbulento para a sociedade brasileira. Para alcançar esse objetivo, utilizou-se como metodologia a pesquisa bibliográfica. Nesse sentido, referenciamo-nos na discussão sobre o papel do psicólogo, na perspectiva de Martín-Baró, para discutir o compromisso do profissional com o processo de conscientização das pessoas. Conforme as discussões empreendidas, foi possível descortinar os movimentos de atuação que corroboravam com a manutenção do sistema, ou seja, que compactuavam com práticas repressivas, mas também, os movimentos que buscavam promover a conscientização, ou mesmo dispor a Psicologia a serviço dos menos favorecidos, mesmo que de modo clandestino.
\end{abstract}

Palavras-chave: Psicologia, Ditadura Civil Militar, Ignácio Martín-Baró, Atuação do psicólogo.

\section{The Psychological practice during the Military Civilian Dictatorship}

\begin{abstract}
This article presents a discussion about the psychological practice in the era of the military civilian dictatorship, in order to answer the following question: Has Brazilian Psychology been at the service of the civilian military dictatorship or of society? Considering that the regulation of the profession of the psychologist in 1962 coincided with the dictatorial period experienced in Brazil between 1964 and 1985, we aimed to discuss the development of Psychology as a science and profession in this turbulent context for Brazilian society. To reach this objective, the bibliographic research methodology was used as methodology. In this sense, we refer to the discussion about the role of the psychologist in the perspective of Martín-Baró to discuss the commitment of the professional with the process of awareness of the people. According to the discussions, it was possible to reveal the psychological practices that supported the maintenance of the system, that is, that compacted with repressive actions, but also, the practices that sought to promote awareness, or even used psychology at the service of the less favored, even if clandestinely.
\end{abstract}

Keywords: Psychology, Military Civilian Dictatorship, Ignácio Martín-Baró, Psychologist's Performance. 


\title{
El Quehacer Psicológico de la Dictadura Civil Militar
}

\begin{abstract}
Resumen: El presente artículo presenta una discusión sobre el quehacer psicológico en la época de la dictadura civil militar, con el objetivo de responder al siguiente cuestionamiento: ¿La Psicología brasileña estuvo al servicio de la dictadura civil militar o de la sociedad? Considerando que la reglamentación de la profesión de psicólogo en 1962 coincidió con el período dictatorial vivido en Brasil entre los años 1964 a 1985, tenemos el objetivo de discutir sobre el desarrollo de la Psicología como ciencia y profesión en este contexto turbulento para la sociedad brasileña. Para alcanzar ese objetivo, se utilizó como metodología la investigación bibliográfica. En ese sentido, nos referimos a la discusión sobre el papel del psicólogo, en la perspectiva de Martín-Baró para discutir el compromiso del profesional con el proceso de concientización de las personas. Conforme a las discusiones emprendidas, fue posible desvendar las prácticas que apoyaban el mantenimiento del sistema, o sea, que eran complacientes con prácticas represivas, y también, los movimientos que buscaban promover la concientización, o incluso poner la psicología al servicio de los menos favorecidos aunque de forma clandestina.

Palabras clave: Psicología, Dictadura Civil Militar, Ignacio Martín-Baró, Actuación del Psicólogo.
\end{abstract}

\section{Introdução}

O presente artigo originou-se a partir das discussões em um grupo de estudo, bem como pela relevância em compreender os impactos da ditadura civil-militar sobre a Psicologia como ciência e profissão. A partir das discussões sobre o papel do psicólogo, na perspectiva de Martín-Baró (1997), questionou-se: a Psicologia brasileira esteve a serviço da ditadura ou da sociedade? Considerando que a regulamentação da profissão de psicólogo ocorreu com a Lei $\mathrm{n}^{\circ} 4.119$, em 27 de agosto de 1962 (Brasil, 1962), e menos de dois anos depois ocorreu, em 31 de março de 1964, o golpe e a instauração do regime militar que vigorou no Brasil entre os anos de 1964 a 1985, objetivamos discutir sobre o desenvolvimento da Psicologia como ciência e profissão neste contexto turbulento para a sociedade brasileira. Para alcance desse objetivo, utilizou-se como metodologia a pesquisa bibliográfica. $\mathrm{O}$ artigo está divido nos tópicos: o papel do psicólogo de acordo com Martín-Baró; a Psicologia no período da ditadura civil militar (lado A e lado B) e considerações finais.

\section{O papel do psicólogo de acordo com Ignácio Martín-Baró (1942-1989)}

A escolha do referido autor, para subsidiar o presente artigo, deve-se às particularidades encontradas em sua história como psicólogo atuante na área sociocomunitária em El Salvador, na América Central. Vale ressaltar o contexto de exceção política que a socie- dade salvadorenha vivenciava, bem como as contribuições dos seus estudos sobre o papel do psicólogo que suscitaram reflexões acerca do papel do psicólogo brasileiro no período da ditadura civil-militar.

De acordo com Oliveira e Guzzo (2013), Ignácio Martín-Baró nasceu na Espanha em 1942 e estudou na Escola Jesuíta de São José, onde desde cedo se identificou com os ideais religiosos e, posteriormente, aderiu à Companhia de Jesus aos 17 anos.

Nos anos 1960, ele foi para a América Latina em missão jesuíta e cursou Psicologia em El Salvador na Universidade Centro-Americana (UCA) que, conforme problematizam Mendonça e Lacerda Júnior (2015), é uma instituição criada em 1965, como demanda da elite nacional.

Em 1979 tornou-se doutor em Psicologia Social e Organizacional, ao defender sua tese na Universidade de Chicago, EUA. Ao retornar do doutorado assumiu vários cargos na UCA, inclusive como de vice-reitor e editor da revista Estudios Centro-americanos (Oliveira, \& Guzzo, 2013).

O compromisso de Martín-Baró foi com a população salvadorenha, mas seu legado ultrapassou os limites geográficos e culminou com a reconhecida Psicologia da Libertação que: "se coloca como uma concepção diferenciada dentro do campo teórico da Psicologia, pelo seu compromisso epistemológico, ético e político com as maiorias populares" (Oliveira, \& Guzzo, 2013, p. 2). Essa dimensão da atuação do psicólogo fundamenta o entendimento sobre qual deve ser o papel do 
psicólogo como profissional que trabalha para possibilitar o empoderamento, a emancipação, a desalienação, seja em que área de atuação ele estiver.

O trabalho compromissado de Ignácio Martín-Baró teve um preço alto, pois custou sua vida. Em 1989 foi emitida uma ordem do alto escalão militar e dos assessores norte-americanos para assassinar os intelectuais jesuítas da Universidade, que eram acusados de serem comunistas, terroristas e de apoiarem as guerrilhas de resistência. Martín-Baró, o reitor Ignácio Ellacuria, também jesuíta, além de outros jesuítas foram alvejados em sua moradia dentro da Universidade (Oliveira, \& Guzzo, 2013).

Para Martín-Baró (1997), antes de pensarmos sobre o papel do psicólogo, precisamos refletir sobre o contexto social no qual ele atua, entendendo que esse profissional faz parte dele. Todas as profissões encontram-se a serviço de uma estrutura social mais ampla e, assim, é a Psicologia. Sobre o papel do psicólogo o autor afirma que:

trabalhar não é apenas aplicar uma série de conhecimentos e habilidades para a satisfação das próprias necessidades; trabalhar é, antes e fundamentalmente, fazer-se a si mesmo, transformando a realidade, encontrando-se ou alienando-se nesse quefazer sobre a rede das relações interpessoais e intergrupais. [...] A luz desta visão da psicologia, pode-se afirmar que a conscientização constitui-se no horizonte primordial do quefazer psicológico (Martín-Baró, 1997, p. 15).

Diante do exposto, o papel do psicólogo transcende a simples aplicação de técnicas psicológicas e desenvolvimento de posturas estereotipadas. Para isso, o profissional deve conhecer a realidade em que vive, não se satisfazendo em apenas executar um trabalho, mas visando construir uma Psicologia que transforme a realidade, promovendo mudanças.

Independente das abordagens ou dos locais de atuação, o que deve importar ao psicólogo é a promoção da conscientização, corroborando com os processos de rompimento das alienações, questionando os paradigmas dominantes.

Nosso psicólogo "salvadorenho" (já que adotou o país centro-americano) acreditava que a Psicologia poderia tornar-se uma Psicologia da Libertação por meio da parceria com outras áreas das ciências sociais. Assim, sua obra recebeu grande influência do educador e escritor brasileiro Paulo Freire, sobretudo com sua proposta de alfabetização conscientizadora (Martín-Baró, 1997, 2006). Esse conceito de conscientização articula: "[...] la dimensión psicológica de la consciência personal com su dimensión social y política, y pone de manifesto la dialéctica histórica entre el saber y el hacer" (Martín-Baró, 2006, p. 7). Essa parceria revela a necessidade de repensarmos o papel da Psicologia como uma profissão que pode e deve levar as pessoas a tomarem conhecimento da realidade, afinal, qual a melhor forma de conhecermos o mundo a nossa volta, senão, pela leitura e escrita? Obviamente os psicólogos não são os profissionais que alfabetizam, mas o que se sugere é que sejam conhecidos os mecanismos pelos quais é possível conscientizar as pessoas de sua realidade. Nesse ponto, Martín-Baró (2006) é taxativo ao afirmar que é dada pouca importância ao estudo crítico da obra de Paulo Freire.

Essa discussão, embora haja sido iniciada em 2013, durante o Concurso de Artigos "Psicologia e Direitos Humanos", como uma das ações do Conselho Federal de Psicologia, juntamente com a publicação do livro "A verdade é revolucionária: testemunhos de psicólogas e psicólogos sobre a ditadura civil-militar brasileira", nunca foi tão atual, à medida que identificamos uma sociedade cada vez mais carente de conscientização, alienada pelos meios de comunicação e que se satisfaz com o entretenimento por meio das redes sociais, tem ficado mais doente com transtornos de ansiedade e de depressão (Conselho Federal de Psicologia, 2013). Mas essa é uma polêmica que ficará para outros artigos.

O que urge, neste momento, é discutirmos amplamente o que significa resgatar a obra de Martín-Baró para entender o papel do psicólogo. Segundo Moreira e Guzzo (2015, p. 570), o resgate da obra desse autor constitui a recuperação "da práxis constituída na, para e com a América Latina”, o que significa pensar em uma Psicologia latino-americana que percebe os problemas e dilemas desse "povo marcado, povo feliz" (alusão à música de Zé Ramalho, "Admirável gado novo", gravada em 1979 [Ramalho, 1979]).

De acordo com Cecília Santiago (Fachin, 2009), Baró acreditava em fazer uma Psicologia política que considere o poder social na configuração do psiquismo humano, contribuindo para construção do poder histórico como requisito de uma nova identidade psicossocial dos povos oprimidos. Para isso, estabeleceu três tarefas libertadoras para a Psicologia 
social latino-americana: o estudo das formas de consciência popular, o resgate e a potenciação das virtudes populares e a análise das organizações populares como instrumento de libertação histórica.

Martín-Baró nos convida a desvendar um dos motivadores para o início da Psicologia científica, a consciência. Esse é o caminho para examinar criticamente o papel do psicólogo. Essa consciência que não se limita ao âmbito privado do saber das pessoas, mas ao âmbito em que cada ser humano encontra o impacto refletido de seu ser e seu fazer na sociedade. A consciência é o saber sobre si e sobre o mundo a sua volta, que "só condicionada parcialmente se torna saber reflexivo" (Martín-Baró, 1997, p. 14).

O processo de conscientização possui três aspectos. O primeiro é que o homem se transforma ao modificar sua realidade, por um processo dialético, que somente será possível mediante o diálogo, e não a imposição. O segundo é que à medida que o homem vai decodificando seu mundo, ele apreende os mecanismos que o oprimem e desumanizam, deixando de entender a situação opressora como natural. E o terceiro aspecto relatado pelo autor é que o novo saber desse homem acerca de sua realidade o leva a um novo saber sobre si mesmo e sua identidade social e "assim, a recuperação de sua memória histórica oferece a base para uma determinação mais autônoma do seu futuro" (Martín-Baró, 1997, p. 16).

Mas, afinal, como é possível colocar em prática esse processo de conscientização? A obra de Baró foi escrita em meados de 1980, mas, mesmo hoje, a minoria dos psicólogos se detém a estudar sistematicamente seus ensinamentos. Fato é que os psicólogos brasileiros passaram por uma reviravolta sobre seu papel antes elitizado para um papel profissional mais aliado às necessidades da população. Sobretudo com a inserção dos psicólogos no corpo técnico das equipes dos Centros de Referência da Assistência Social, mediante a democratização do país e sua inserção nos concursos públicos (Silva, \& Corgozinho, 2011). Mesmo assim, essa ainda parece uma tarefa difícil para o psicólogo.

A partir de sua realidade de guerra, Baró oferece alguns apontamentos sobre como pode ser o chamado "quefazer" do psicólogo a fim de buscar a desalienação de pessoas e grupos. Seu exemplo remete ao caso das vítimas de guerra, que devem receber uma atenção especial por meio da extensão de atendimento clínico a grupos majoritários. Porém, a seu ver, esse atendimento deve promover a conscientização e devolver a palavra às pessoas, como indivíduos e como parte do povo. Para Martín-Baró (1997, p. 20), essa clínica precisa "apontar diretamente para o desaparecimento de uma identidade social cultivada sobre os protótipos do opressor e do oprimido, e a configurar uma nova identidade das pessoas enquanto membros de uma comunidade humana, responsáveis por uma história”. Em síntese, esse olhar deve ser o mesmo em todas as outras áreas de atuação, seja a escola, a organização, ou o hospital.

A ideia de Martín-Baró vai além de atribuir ao psicólogo um papel de agente transformador, mas de um agente revolucionário. Em uma exposição em 1980, o autor expressa que o psicólogo deve fazer parte do processo revolucionário, entendendo que uma revolução é mais que enfrentar situações difíceis em uma dada ordem social, mas é um processo que visa modificar a ordem social. Para isso, o psicólogo deve ser um bom psicólogo e, também, ser um psicólogo do povo, que atue e acompanhe a nova ordem social almejada. Para essa nova ordem estão questões como: satisfazer as necessidades do povo, mudar a mentalidade da sociedade (com valores de solidariedade e responsabilidade) e atacar os vícios da sociedade capitalista, sobretudo a corrupção (Martín-Baró, 2017).

É possível afirmar que o legado teórico de Martín-Baró nunca foi tão atual e provocador, em um momento em que o Brasil e outros países no mundo vivem assolados por pobreza, guerras e turbulências políticas, sociais e econômicas. É preciso que os psicólogos comecem a se inteirar dessas discussões e busquem apoio do entendimento sobre os processos de conscientização, começando a conscientizarem a si mesmos sobre seu papel na sociedade como agente político ou transformador, que atua para mudar as formas de pensar e fazer, de si e do outro, o povo.

De acordo com Furtado (2000), toda Psicologia é política. O que não significa que a Psicologia deve ser classista e unicamente a serviço da classe de trabalhadores explorados, mas que deve parar de olhar apenas para o lado daqueles que podem pagar. Deve reinventar-se e compreender o processo de conscientização sob o ponto de vista da grande plasticidade da consciência psicológica que leva o sujeito para autonomia de si no mundo (Furtado, 2000).

Ter o psicólogo como agente do processo revolucionário implica visitarmos a história profissional, verificando os momentos de atuação que fortaleceram a alienação da classe e do povo, mas também os momentos de atuação que de alguma forma rompe- 
ram com o status quo estabelecido. Então, a seguir, discutiremos o desenvolvimento da Psicologia no contexto da Ditadura civil militar no Brasil, iniciando pelo momento em que o psicólogo esteve em parceria com o sistema ditatorial e, posteriormente, apresentando os movimentos em que psicólogos buscaram romper com as práticas de atuação dominantes.

\section{A Psicologia no período da ditadura civil-militar: dois recortes históricos}

O presente artigo está dividido em dois lados da história da Psicologia durante o período da ditadura civil-militar. Não se pretende extenuar todos os acontecimentos documentados sobre as duas versões, mas problematizar o papel do psicólogo que, nesse momento da história, ora atua calado e calando e ora atua para transformar a realidade a sua volta. Por isso, convencionou-se denominar lado A e lado B, estabelecendo que o objetivo não é a crítica pela crítica aos que atenderam a interesses governamentais, mas registrar fazeres $p s i$, instigando a refletir sobre o que aconteceu e como "devemos" acontecer.

Para isso, inicialmente, recorremos à canção de Zé Ramalho, "Admirável gado novo" (Ramalho, 1979), inspirada na obra de Aldous Huxley, "Admirável Mundo Novo". Há um trecho que diz: "Lá fora faz um tempo confortável, a vigilância cuida do normal". Esse lado da canção nos lembra a postura acomodada e, ao mesmo tempo, conivente dos profissionais psicólogos. E analisando o contexto social, veremos que mesmo as entidades da época estavam dominadas pela política do medo.

Em outro trecho: "E ter que demonstrar sua coragem, à margem do que possa parecer", inspirados pela mesma canção, vemos que, ante um cenário opressor e punitivo, pessoas se revelaram corajosas o suficiente para agir, fosse como opositores ao sistema, fosse como profissionais agindo na clandestinidade junto às comunidades, mesmo que exercendo trabalhos voluntários. Assim como o psicólogo Martín-Baró, cuja obra proporciona o entendimento sobre o papel do psicólogo como agente que leva o outro a pensar além.

Ante os dois lados, será possível responder a questão norteadora da pesquisa: a Psicologia brasileira esteve a serviço da ditadura ou da sociedade?

\section{Lado A: a Psicologia em favor do Estado}

Embora já existisse a atuação da Psicologia há cerca de 30 anos nas áreas consideradas tradicionais (clínica, escolar e organizacional), a regulamentação como profissão se deu apenas em 1962. Segundo Bernardes (2004), algumas conquistas da Psicologia teriam sido retardadas com o Golpe Militar de 1964. A partir desse acontecimento, pode-se afirmar que, em seu desenvolvimento, a Psicologia caracterizou-se pelo "obscurantismo, pelas delações, pelos rompimentos com compromissos éticos, políticos e sociais fundamentais para o convívio com a sociedade" (Bernardes, 2004, p. 95). Ou seja, a atuação dos profissionais, em sua maioria, esteve aliada aos interesses da minoria no poder.

De acordo com Scarparo e Ozorio (2009), no período da exceção política, lacunas e silêncios marcaram os fazeres $p s i$. As autoras esclarecem que existiu nesse período um processo de assimilação do sistema que impulsionava os estudantes e psicólogos a não se envolverem no regime opressor "no caso do Brasil, nos anos da ditadura, as práticas psicológicas contribuíram para calar o grito dos injuriados, a indignação dos desrespeitados e o livre pensar" (Scarparo, \& Ozório, 2009, p. 1). Assim, desse entendimento incorre pensar que a atuação do psicólogo se restringia a manter as aparências, fingindo que nada estava acontecendo ou ainda endossando práticas arbitrárias, o que corresponde a um papel profissional bem divergente da proposta de Martín-Baró, que enfatiza uma atuação promotora de conscientização e livre de padrões preconcebidos.

Nesse período, o Brasil teve sua economia direcionada pela lógica do neoliberalismo, o que influenciou significativamente a Psicologia como ciência e profissão. Conforme essa lógica, deve haver o mínimo de intervenção do estado na economia, marcada pelo livre comércio e, tal como vivemos atualmente, a constante privatização de instituições estatais. Para Bernardes (2004), antes mesmo da profissão ser regulamentada, o psicólogo já era visto como profissional liberal e sem vinculações hierárquicas.

Esse panorama favorecia a atuação do psicólogo na área clínica e passou a ser um modelo de atuação hegemônico, também denominado como "modelo médico" (Antunes, 2012). O chamado milagre econômico favoreceu a classe média, que passou a procurar mais o psicólogo, como o clínico. Porém, as outras atuações, como escolas e organizações também cresceram. A atividade do psicólogo nesses setores era movida pela lógica neoliberal, centrada no indivíduo e no mercado (Bernardes, 2004). 
Nesse sentido, Batitucci (1978, p. 141) afirmou que a formação do psicólogo empresarial: "para ser válida deve necessariamente atender às necessidades e demandas da empresa, por isso, nunca pode ser dirigida a Psicologia em si mesma, mas sim a Psicologia que a empresa precisa para resolver seus problemas humanos e organizacionais". Essa assertiva evidencia que, nesse período, a atuação do psicólogo estaria distante dos interesses da maioria da população, ou seja, dos menos favorecidos da sociedade. O que prevalece é a lógica mercadológica, contribuindo para uma Psicologia elitizada.

Neste recorte da história da Psicologia brasileira, não vemos uma profissão para o povo pobre e vulnerável, mas aliada aos interesses de uma minoria rica e no poder, como esclarece Hur (2013, p. 2), ao afirmar que a "psicologia brasileira manteve-se elitista e assumiu a matriz cientificista e positivista importada dos Estados Unidos com fortes traços normalizadores e adaptativos". Assim, como em uma brincadeira infantil de encaixe, as teorias advindas de outras nações eram traduzidas e utilizadas pelos profissionais, na realidade brasileira, sem haver uma preocupação com o contexto cultural do povo, que deveria encaixar-se nos padrões esperados. Essa realidade configura uma Psicologia que prima pela adaptação do homem ao seu meio.

Nesse cenário neoliberalista, com atos de violência e intensa censura do livre pensar e agir, surge o fenômeno "cultura psi" (Bernardes, 2004; Dimenstein, 2000; Figueiredo, 1993), que corresponde a um movimento de disseminação das ideias advindas da Psicologia, psiquiatria e psicanálise, tornando-as acessíveis à população e divulgando uma lógica intimista, que culpabiliza o sujeito pelo problema que apresenta, desconsiderando o entorno social no qual ele está inserido.

Assim, a Psicologia, nesse recorte, esteve atrelada ao militarismo e Bernardes (2004, p. 96-97) é incisivo ao afirmar que "o universo psi sobrevive nos porões da ditadura, alimentando o terrorismo de Estado, torturando e silenciando". O autor discorre sobre a atuação de profissionais da Psicologia compactuando com a repressão. Pode-se inferir uma Psicologia antiética e vergonhosa, pois sugere ir contra os direitos humanos hoje tão discutidos, embora ainda não tão respeitados.

Coimbra (2011) esclarece que os psicólogos atuantes em parceria com o Regime Militar exerciam práticas caracterizadas pelo uso de ferramentas psicológicas como a aplicação de anamneses ou de testes psicológicos (de personalidade, de inteligência etc.) que classificavam e rotulavam os sujeitos da oposição, como desestruturados ou desajustados. Esse entendimento advém da pesquisa do "Perfil Psicológico do Terrorista Brasileiro", realizada por uma entidade de Psicologia que buscou explicar as causas que levaram os militares presos na época a participarem da luta armada.

O período de exceção política e democrática pelo qual o Brasil passou durou 21 anos, e isso foi decorrente das práticas de diversos profissionais que permitiram, através de suas explicações teóricas e exercícios profissionais que o terrorismo de Estado continuasse operando (Coimbra, 2001).

Sobre as entidades de Psicologia da época, vale ressaltar que foi em meio à ditadura civil-militar que foram criados o Conselho Federal e sete Conselhos Regionais de Psicologia. Segundo a psicóloga Coimbra (2011), a criação dos conselhos se deu: "no auge do terrorismo de Estado, quando as perseguições se davam de uma forma totalmente naturalizada". Para ela, todos aqueles que estivessem contra o regime eram inimigos internos e, inclusive, a Lei $\mathrm{n}^{\circ}$ 5.766, de 20 de dezembro de 1971 (Brasil, 1971), que criou os Conselhos (Federal e Regionais), é considerada autoritária e centralizadora, pois não possibilitava a discussão com a categoria. Pode-se imaginar o cenário preocupante que se apresentava aos formandos de Psicologia, visto que os órgãos regulamentadores da profissão estariam também contaminados por ideias autoritárias e alienantes.

Aliás, causa estranhamento o fato de os Conselhos serem criados durante o período da ditadura civil militar. Sobre isso, Hur (2012) esclarece o receio do Estado quanto à organização da sociedade civil. Por esse motivo, foi criada a lei que instituía a profissão de psicólogo e, apenas anos depois, foram criados órgãos para fiscalizar e regulamentar a categoria.

No entanto, contraditoriamente é nesse período ditatorial que os psicólogos se organizam para criar os conselhos; os psicólogos voltam a se reorganizar justamente quando há um refluxo e uma intensa repressão aos movimentos sociais. A organização dos psicólogos não foi feita como um movimento social, reivindicador, e sim numa ação institucionalizada, direta, com os representantes do Estado da ditadura (Hur, 2012, p. 74).

Isso nos revela que os profissionais da época precisaram entrar em acordo com os governos a fim de institucionalizarem a organização da categoria. 
A organização da classe dos profissionais de Psicologia, conforme Hur (2012), emerge como ação institucionalizada, atrelada ao Estado, sem caracterização de movimento social e reivindicador. Institui-se, inicialmente, as Associações como protótipo de Sindicado, ligadas a questões técnicas para a consolidação das práticas. Com a associação de um terço dos profissionais de Psicologia do estado de São Paulo, no ano de 1973, cria-se o Sindicato do referido estado, instalando-se o Conselho Federal no mesmo ano.

De acordo com Bernardes (2004), os documentos encontrados nesse período foram todos produzidos pelo Estado e apresentam forte caráter normativo e regulador e, em seu entender, isso justifica a escassa produção científica das entidades de Psicologia.

Ante o exposto, a Psicologia como ciência e profissão sofreu grandes consequências do contexto político e econômico brasileiro com atividades que são consideradas antiéticas e que impactavam as subjetividades humanas no sentido de calar os opositores ao Estado.

\section{Lado B: a Psicologia em favor da Democracia}

Sobre as discussões do papel do psicólogo até aqui, tem-se uma visão de que a Psicologia como ciência e profissão esteve aliada aos interesses do Estado. Contudo, faz-se necessário pontuar a existência de pequenos movimentos que agiam no sentido de tentar romper as práticas psicológicas alienantes favorecedoras do Regime Militar.

Um exemplo disso foi o fato de ter havido psicólogos e estudantes de Psicologia perseguidos pelos militares por se envolverem diretamente nos atos revolucionários e de resistência ao regime militar, como citado por Arantes (2012) no artigo intitulado "Em nome da memória". O estudo apresenta cinco histórias de jovens mulheres, estudantes e profissionais de Psicologia, que foram torturadas e assassinadas durante a ditadura civil militar. Essa talvez seja parte da história que ninguém vê ou discute na academia e que constitui um aspecto fundamental, para que situações como essas não mais se repitam.

Como o caso de Aurora Maria Nascimento Furtado, estudante de Psicologia na Universidade de São Paulo. Em 1968, a jovem respondia pelo setor de imprensa da União Estadual dos Estudantes de São Paulo. Em 1972, foi presa por policiais no Rio de Janeiro, com 26 anos de idade. Aurora foi torturada no pau de arara, com sessões de eletrochoque, espancamentos, afogamento e queimaduras. Seu rosto ficou deformado devido à utilização do instrumento "coroa de cristo", que apertava o crânio do torturado. A fim de encobrir seu assassinato, seu corpo foi jogado em uma rua no Rio de Janeiro e os órgãos da Repressão divulgaram na imprensa que a jovem morreu em uma troca de tiros com a polícia (Arantes, 2012). A história dessas mulheres revela que haviam ações de militância por parte de psicólogas em favor dos direitos humanos brasileiros.

Além das histórias particulares de pessoas que individualmente se opuseram ao Estado, fato que pouco ou nada se fala no ambiente acadêmico, sobretudo nas aulas de história da Psicologia, cabe resgatar a criação de uma revista carioca muito importante para revelar um movimento social dos psicólogos. No período compreendido ente 1976 e 1981, paralelo ao surgimento de uma Psicologia Crítica no Brasil, dá-se à trajetória da "Rádice", uma revista de Psicologia que possuía como público-alvo o universo $p s i$, pessoas interessadas em Psicologia, psicanálise e psiquiatria.

A revista lançava o olhar a vários assuntos como as lutas travadas no âmbito da saúde mental, discussões sobre o currículo da formação, as novas regulamentações da profissão e, até, as denúncias de torturas e desaparecimentos daqueles que lutavam contra $o$ regime militar tanto no Brasil, como em outros países da América Latina. Em seu primeiro número, trouxe um artigo do psicólogo Carlos Ralph, que fez uma crítica às práticas hegemônicas da época. A revista, que se tornou posteriormente um jornal, é considerada pelos autores Santos e Jacó-Vilela (2005, p. 26) “um dos poucos dispositivos de divulgação do pensamento de outras formas de se fazer psicologia”.

Outro exemplo pode ser verificado no texto de Freitas (2008), em que a autora sistematiza os períodos de atuação do psicólogo na comunidade, no Brasil, nas décadas de 1960 a 1990. Assim, o trabalho do psicólogo comunitário na década de 1960 se caracterizava por ser voluntário, não remunerado, no qual o psicólogo era convicto do papel político junto aos setores menos favorecidos da população. Entretanto, Freitas (2008) explica que era uma atividade "tímida". Já na década de 1970, os profissionais de Psicologia passaram a atuar em novos espaços, fora das clínicas, escolas e empresas, inserindo-se em associações de bairro, comunidades eclesiais ou favelas por meio de práticas diferentes das que estavam acostumados a exercer. Os psicólogos desse período chegaram a se envolver em atividades como de assistência psicológica gratuita à população, 
promoção de reuniões, discussões e levantamentos descritivos sobre as necessidades da população, participação em abaixo-assinados e passeatas.

Em meados de 1980, devido ao movimento de abertura democrática, a atividade do psicólogo comunitário, que era clandestina e não remunerada, passou a ser repensada. A atividade começou a receber mais atenção e ser mais discutida, inclusive nos cursos de formação, nas conferências e em artigos, haja vista que muitos dos psicólogos comunitários eram também professores.

Considera-se que esse movimento de atuação era semelhante à proposta de Martín-Baró (1997) para o "quefazer" psicológico. Assim, conclui-se a outra parte da pergunta sobre a quem serviu a Psicologia.

Esse lado B apresenta a outra face da história, tantas vezes esquecida na formação do psicólogo, pois revela a possibilidade de exercer uma Psicologia política ou uma Psicologia da libertação. Dessa forma, destaca-se a impossibilidade de separação entre Psicologia e política:

[...] pois a psicologia trabalha com sujeitos habitantes de um lugar em determinado momento histórico da sociedade. Diante disso, qualquer intervenção realizada com os sujeitos produz efeito no coletivo, sempre havendo uma implicação política, pois essa prática é sempre uma ação sobre a vida desses sujeitos. Estar atento a isso é o que vai diferenciar os profissionais que se colocam em uma postura ético-política, ou seja, que se comprometem com o cuidado relativo à vida dos sujeitos que afetam (Reis, \& Guareschi, 2010, p. 857).

Tal como Reis e Guareschi (2010) discorrem, Psicologia e política se inter-relacionam e o que precisamos é de posturas mais democráticas, pois cada prática $p s i$ é capaz de alterar de algum modo a vida das pessoas. Entender a profundidade dessas ações é o que corrobora para uma atuação ética e compromissada com a sociedade.

Sobre as situações ora relatadas (Arantes, 2012; Freitas, 2008; Santos, \& Jacó-Vilela, 2005), podemos inferir que retratam fazeres $p s i$ mais parecidos com a proposta de Martín-Baró (1997), que visava refletir sobre as problemáticas sociais, aproximando a Psicologia das classes menos favorecidas e majoritárias da população, passando a se inserir em situações novas, porém diversas.

Assim, cabe discutir sobre até que ponto, delimitar a Psicologia como uma ciência e profissão aliadas apenas aos interesses elitistas e ditatoriais pode ser uma análise reducionista.
Pois o destino de quem se opusesse ao Estado ou atuasse em favor da conscientização das massas era torturas e assassínios. Sem chance de defesa, sem julgamento justo e sem a divulgação e esclarecimento sobre a verdade por trás das histórias das psicólogas ou das estudantes de Psicologia. Não nos esquecendo ainda da revista "Rádice" como meio de conscientização dos profissionais psicólogos ou as ações de profissionais na comunidade.

Esses "lados" precisam ser mais revelados, mais discutidos, desde a formação universitária, bem como precisa vir à reflexão de profissionais psicólogos para nortear sua atuação, em qualquer espaço que ele estiver (clínica, escola, organizações, entre outros), independentemente de abordagens de mundo, pois vê-se muitas discussões improdutivas na Psicologia, no campo filosófico, que muito atrapalham o crescimento da profissão como categoria. Essa discussão pode promover maior sentimento de união à classe, e evitar que práticas inadequadas sejam desenvolvidas novamente.

\section{Considerações finais}

O presente artigo buscou responder à questão: a Psicologia brasileira esteve a serviço da ditadura civil militar ou da sociedade? Para responder tal questionamento, foi realizado um levantamento bibliográfico acerca das práticas desenvolvidas na época do governo militar.

Diante das discussões construídas até aqui, verificou-se que a atuação do psicólogo esteve majoritariamente atrelada aos interesses do Estado. Essa postura contribuiu para a construção de uma Psicologia elitizada e distante das classes menos favorecidas, evidenciando uma prática normalizadora, adaptativa ao sistema, com técnicas estereotipadas, restringindo-se as aparências e endossando práticas arbitrarias. O que responde parcialmente ao questionamento que norteou as discussões, considerando que a Psicologia como ciência e profissão esteve a serviço da ditadura civil militar, ponto bastante divergente das propostas de Martín-Baró.

Paralelamente às práticas alienadas e alienantes, emergiram, no bojo das inquietações do período ditatorial, tímidas atuações de grupos isolados que lutaram para romper os paradigmas dominantes. Verificou-se a existência de estudantes e psicólogos que se envolveram diretamente no movimento opositor, que foram duramente torturados e executados. Além disso, encontrou-se registros da participação de psicólogos em área pouco explorada até a década de 1960: a Psicologia comunitária, que nasceu com o propósito de colocar 
a Psicologia a serviço dos setores menos favorecidos da sociedade. Como vimos, eram atuações clandestinas, voluntárias e não remuneradas, mas já vislumbravam as preocupações com o contexto social em que o psicólogo estava inserido e, poderia se inserir, refletindo sobre as necessidades da população, buscando romper as práticas alienantes que favoreciam o Regime Militar.

Considera-se que esse movimento de atuação era semelhante à proposta de Martín-Baró (1997) para o "quefazer" psicológico. Assim, conclui-se a outra parte da pergunta sobre a quem serviu a Psicologia.

Destarte, convém responder que a dicotomia proposta no questionamento norteador foi superada à medida que identificamos mais movimentos profissionais coniventes com o regime opressor da época. Contudo, entende-se que o clima era de tensão e medo, assim, não podemos simplesmente culpabilizar os profissionais por entendermos que os processos de coerção foram estendidos a todos, inclusive aos psicólogos que partilharam práticas aliadas ao governo. Devemos, sim, utilizar os conhecimentos adquiridos com essas experiências para seguir na construção de uma Psicologia a serviço da sociedade, negando-nos a agir de forma a transgredir a ética profissional que nos rege.

Refletir e pesquisar sobre essa realidade vivenciada nas práticas dos profissionais da Psicologia em meio à ditadura possibilita profundos questionamentos e reflexões para a construção do fazer da Psicologia na contemporaneidade. Todas as provocações aqui apresentadas oportunizam recordar e concluir que somos uma geração (de psicólogas e psicólogos) marcada por experiências de silenciamento, perdas e dores, ao tempo que também recebemos como herança práticas de lutas pelos rompimentos de vivências alienadas.

Isso corresponde à possibilidade de um resgate histórico que contribui para ressignificar nossas identidades sociais e pessoais como parte do, ainda, "povo marcado", mas "povo feliz" que continua, mesmo após mais de 50 anos de criação dessa profissão, buscando entender: qual o nosso papel nessa sociedade? Como podemos de fato agir com compromisso social e ético?

Discutir o papel do psicólogo revela a necessidade contínua de uma prática que não se esquive de seus princípios fundamentais, tão claros no Código de Ética Profissional. É construir um hoje com atitudes que atendam às necessidades das pessoas, ou seja, como prestadores de serviço para o social e coletivo, contribuindo para a ampliação de consciências, ajudando as pessoas a superarem situações alienantes, considerando os contextos vivenciados e os impactos da sua atuação profissional frente aos sujeitos.

As discussões até aqui empreendidas possuem caráter preventivo, pois podem evitar práticas elitistas e normalizadoras, mas também caráter interventivo, por vislumbrar caminhos a seguir, sugerindo aos psicólogos que mantenham uma postura crítica frente a sua realidade. Ainda assim, frente a uma realidade opressora e paradigmática, que esse profissional conscientize-se sobre seu papel, que não aceite também ser violentado com cenários de desvalorização e que transforme a si mesmo, para transformar o outro em sua jornada. Por tanto, que seja um "quefazer" baseado nos aspectos da conscientização de transformação de si, decodificação da realidade e transformação da realidade.

Nesse contexto, as ideias de Baró serviram de inspiração para compreender que o papel do psicólogo remete à possibilidade de transformação de si e do outro, por meio do processo de conscientização que deve ser o objetivo principal do fazer psicológico. Será mais produtivo, para a Psicologia como ciência e profissão, bem como para a constituição da identidade desse profissional, discutir nas universidades formadoras o papel do psicólogo, ao invés de grupos se digladiarem discutindo questões frívolas como: a melhor opção de abordagens para atuação na área clínica ou mesmo sobre as áreas de atuação que mais promovam retorno financeiro para o profissional.

Infelizmente, o que vemos hoje são mais pessoas buscando o destaque pessoal em detrimento do grupo, quando o melhor seria vivenciar essa atuação de modo reflexivo e questionador, buscando o compromisso social e, sobretudo, ético, sempre. Enquanto esse sentimento de grupo não for internalizado, a começar pela graduação, dificilmente será possível que o papel do psicólogo seja realmente exercido em conformidade com o que Ignácio Martín-Baró propôs anos atrás.

Se fosse possível considerar o período do governo militar como uma canção, entende-se que, para o desenvolvimento da própria Psicologia como ciência e profissão, seria necessário que a Psicologia dançasse conforme o ritmo. Contudo, não é possível desconsiderar que houve psicólogos e estudantes de Psicologia que buscaram criar novos passos.

Olhar para todo esse passado é entender como se produziu o momento presente, é oportunizar um senso crítico capaz de fortalecer as categorias profissionais, neutralizando processos capazes de produzirem alienação e dominação subjetiva das pessoas. 


\section{Referências}

Antunes, M. A. M. (2012). A Psicologia no Brasil: um ensaio sobre suas contradições. Psicologia: Ciência e Profissão, 32(spe), 44-65. https://doi.org/10.1590/S1414-98932012000500005

Arantes, M. A. A. C. (2012). Em nome da memória. Psicologia: Ciência e Profissão, 32(spe), 310-317. https://doi.org/10.1590/S1414-98932012000500022

Batitucci, M.D. (1978) Psicologia organizacional: uma saída para uma profissão em crise no Brasil. Arquivos Brasileiros de Psicologia Aplicada, 30(1-2), 137-156.

Bernardes, J. S. (2004) O debate atual sobre a formação em Psicologia no Brasil: permanências, rupturas e cooptações nas políticas educacionais (Tese de doutorado). Pontifícia Universidade Católica de São Paulo, São Paulo.

Brasil. (1962, 10 de setembro). Lei No 4.119, de 27 de agosto de 1962. Dispõe sobre os cursos de formação em psicologia e regulamenta a profissão de psicólogo. Diário Oficial da União.

Brasil. (1971, 20 de dezembro). Lei № 5.766, de 20 de dezembro de 1971. Cria o Conselho Federal e os Conselhos Regionais de Psicologia e dá outras providências. Diário Oficial da União.

Coimbra, C. M. B. (2001) Tortura ontem e hoje: resgatando uma certa história. Psicologia em Estudo, 6(2), 11-19. https://doi.org/10.1590/S1413-73722001000200003

Coimbra, C. (2011). As marcas indeléveis da tortura. IHU on line, 9(358), 5-9. Recuperado de http://www.ihuonline. unisinos.br/media/pdf/IHUOnlineEdicao358.pdf

Conselho Federal de Psicologia. (2013). A verdade é revolucionária: testemunhos e memórias de psicólogas e psicólogos sobre a ditadura civil-militar brasileira (1964-1985). Brasília, DF: o autor. Recuperado de http://site.cfp.org. br/wp-content/uploads/2013/12/A-verdade-e-revolucionaria-29-05-2014.pdf

Dimenstein, M. (2000) A cultura profissional do psicólogo e o ideário individualista: implicações para a prática no campo da assistência pública à saúde. Estudos de Psicologia (Natal), 5(1), 95-121. https://doi.org/10.1590/S1413-294X2000000100006

Fachin, P. (2009) A psicologia da libertação segundo Ignácio Martín-Baró. IHU online, 9(318), 26-28. Recuperado de http://www.ihuonline.unisinos.br/index.php?option=com_content\&view=article\&id=3009\&secao=318

Figueiredo, L. C. (1993) Sob o signo da multiplicidade. Estudos de Psicologia, 10(1), 11-19.

Freitas, M. F. Q. (2008) Psicologia na comunidade, psicologia da comunidade e psicologia social comunitária. In H. F. Campos, Psicologia social comunitária (pp. 54-80). Petrópolis, RJ: Vozes.

Furtado, O. (2000) Psicologia e compromisso social: base epistemológica de uma psicologia crítica. Revista Psicologia Social e Institucional, 2(2), 217-229. Recuperado de http://www.uel.br/ccb/psicologia/revista/ artigo\%205.pdf

Hur, D. U. (2012). Políticas da psicologia: histórias e práticas das associações profissionais (CRP e SPESP) de São Paulo, entre a ditadura e a redemocratização do país. Psicologia USP, 23(1), 69-90. https:// doi.org/10.1590/S0103-65642012000100004

Huxley, A. (1979). Admirável mundo novo. Porto Alegre, RS: Globo.

Hur, D. U. (2013). Esquizoanálise e política: proposições para a Psicologia Crítica no Brasil. Teoría y Crítica de la Psicología, (3), 264-280. Recuperado de http://teocripsi.com/documents/3HUR.pdf

Martín-Baró, I. (2017). Crítica e libertação na psicologia: estudos psicossociais (F. Lacerda Júnior, trad.). Petrópolis, RJ: Vozes.

Martín-Baró, I. (2006). Hacia una psicología de la liberación. Revista Electrónica de Intervención Psicosocial y Psicología Comunitaria, 1(2), 7-14. Recuperado de http://www.facso.uchile.cl/psicologia/epe/_documentos/getep/ martin_baro_psicologia_liberacion.pdf

Martín-Baró, I. (1997). O papel do Psicólogo. Estudos de Psicologia (Natal), 2(1), 7-27. <https://doi.org/10.1590/ S1413-294X1997000100002

Mendonça, G. S., \& Lacerda Júnior, F. (2005). A psicologia da libertação e as questões habitacionais: história e constituição. Teoría y Crítica de la Psicología, (6), 102-121. Recuperado de http://www.teocripsi.com/ojs/index.php/ $\mathrm{TCP} /$ article/viewFile/31/28 
Moreira, A. P. G., \& Guzzo, R. S. L. (2015). Do trauma psicossocial às situações-limite: a compreensão de Ignácio Martín-Baró. Estudos de Psicologia (Campinas), 32(3), 569-577. https://doi.org/10.1590/0103-166X2015000300021

Oliveira, L. B., \& Guzzo, R. S. L. (2013). A vida e a obra de Ignácio Martín-Baró: o paradigma da libertação. In Anais do XVIII Encontro de Iniciação Científica, da Pontifícia Universidade Católica, Campinas, SP.

Ramalho, Z. (1979). Adimirável gado novo [LP]. Rio de Janeiro, RJ: Estúdios CBS.

Reis, C., \& Guareschi, N. M. F. (2010). Encontros e desencontros entre Psicologia e Política: formando, deformando e transformando profissionais de saúde. Psicologia: Ciência e Profissão, 30(4), 854-867. https://doi.org/10.1590/S1414-98932010000400014

Santos, A. D., \& Jacó-Vilela, A. M. (2005) Rádice: passado e futuro. Psicolocia \& Sociedade, 17(3), 26-32. https://doi.org/10.1590/S0102-71822005000300004

Scarparo, H. B. K., \& Osório, J. C. (2009). Registros históricos do Conselho de Psicologia da Sétima Região (CRP-07) no período da Ditadura no Brasil. Temas em Psicologia (Ribeirão Preto), 17(1), 93-104. Recuperado de http:// pepsic.bvsalud.org/scielo.php?script=sci_arttext\&pid=S1413-389X2009000100009

Silva, J. V., \& Corgozinho, J. P. (2011). Atuação do psicólogo, SUAS/CRAS e psicologia social comunitária: possíveis articulações. Psicologia \& Sociedade, 23(spe), 12-21. https://doi.org/10.1590/S0102-71822011000400003

\section{Ana Maria Batista Correia}

Mestre em Educação - UFPI. Psicóloga do campus Amílcar Ferreira Sobral - UFPI

E-mail: ana_songs@yahoo.com.br

\section{Carla Náyad Castelo Branco Dantas}

Especialista em Psicopatologia Clínica e Institucional - UNIP. Psicóloga do Instituto Dom Barreto - IDB

E-mail: nayad_carla@hotmail.com

Endereço para envio de correspondência:

Universidade Federal do Piauí. BR 343, sem número, B Meladao,Floriano, PI. CEP 64808 - 605

Recebido: 30/06/2017

Reformulado: 04/09/2017

Aprovado: 15/09/2017

Received: 06/30/2017

Reformulated: 09/04/2017

Approved: 09/15/2017

Recebido: 30/06/2017

Reformulado: 04/09/2017

Aceptado: 15/09/2017

Como citar: Correia, A. M. B., \& Dantas, C. N. C. B. (2017). O fazer psicológico no período da ditadura militar. Psicologia: Ciência e Profissão, 37(n. spe), 71-81. https://doi.org/10.1590/1982-3703050002017

How to cite: Correia, A. M. B., \& Dantas, C. N. C. B. (2017). The psychological practice during the period of the military dictatorship. Psicologia:Ciência e Profissão, 37(n. spe), 71-81.https://doi.org/10.1590/1982-3703050002017

Cómo citar: Correia, A. M. B., \& Dantas, C. N. C. B. (2017). El quehacer psicológico de la época de la dictadura militar. Psicologia: Ciência e Profissão, 37(n. spe), 71-81. https://doi.org/10.1590/1982-3703050002017 